\title{
Defect Healing in Two-Step Deposited Perovskite Solar Cells via Formamidinium Iodide Compensation
}

Chenguang Xin ${ }^{\mathrm{a}, \mathrm{b}}$, Jiangbin Zhang ${ }^{\mathrm{c}, \mathrm{de \#}}$, Xin Zhou ${ }^{\mathrm{a}, \mathrm{b} \#}$, Linchuan $\mathrm{Ma}^{\mathrm{f}}$, Fuhua Hou ${ }^{\mathrm{a}, \mathrm{b}}$, Biao Shi ${ }^{\mathrm{a}, \mathrm{b}}$, Sanjiang Pan ${ }^{\mathrm{a}, \mathrm{b}}$, Bingbing Chen ${ }^{\mathrm{a}, \mathrm{b}}$, Pengyang Wang ${ }^{\mathrm{a}, \mathrm{b}}$, Dekun Zhang ${ }^{\mathrm{a}, \mathrm{b}}$, Xinliang Chen ${ }^{\mathrm{a}, \mathrm{b}}$, Ying Zhao ${ }^{\mathrm{a}, \mathrm{b}}$, Artem A. Bakulin ${ }^{\mathrm{d}}$, Yuelong Li*a,b ${ }^{*}$ Xiaodan Zhang*a,b

${ }^{a}$ Institute of Photoelectronic Thin Film Devices and Technology of Nankai University, Key Laboratory of Photoelectronic Thin Film Devices and Technology of Tianjin, Solar Energy Research Center of Nankai University, \#38 Tongyan Road, Jinnan District, Tianjin 300350, P. R. China.

b Collaborative Innovation Center of Chemical Science and Engineering, Renewable Energy Conversion and Storage Center of Nankai University, \#94 Weijin Road, Nankai District, Tianjin 300072, P. R. China.

${ }^{\mathrm{c}}$ Cavendish Laboratory, University of Cambridge, J J Thomson Avenue, Cambridge, CB3 0HE, United Kingdom.

${ }^{\mathrm{d}}$ Department of Chemistry, Imperial College London, South Kensington Campus, London SW7 2AZ, United Kingdom.

e College of Advanced Interdisciplinary Studies, National University of Defense Technology, Changsha 410073, P. R. China.

${ }^{\mathrm{f}}$ Electronic Information Laboratorial Teaching Center, Nankai University, \#38 Tongyan Road, Jinnan 
District, Tianjin 300350, P. R. China.

*Corresponding author:

Prof. Yuelong Li, lyl@nankai.edu.cn, Tel.: +86-22-85358845; Fax: +86-22-23499304

Prof. Xiaodan Zhang, xdzhang@ nankai.edu.cn, Tel.: +86-22-85358082; Fax: +86-22-23499304

\# These authors contribute equally to this work

Experimental: in the page of S3

Figure: Fig. S1-S7 in the Page S5-S9

Table: Table $\mathrm{S} 1$ in the page of $\mathrm{S} 10$ 


\section{Experimental Section}

Materials: All the chemicals and solvents were used as received without further modifying. The $\mathrm{SnO}_{2}$ colloid precursor was obtained from Alfa Aesar (Tin (IV) oxide). Isopropyl alcohol (IPA), N,Ndimethyl formamide (DMF), and dimethyl sulfoxide (DMSO) were purchased from Alfa Aesar. FAI, methylammonium bromide $(\mathrm{MABr})$, and methylammonium chloride $(\mathrm{MACl})$ were bought from Shanghai Materwin New Materials Co.,Ltd. The 1.3M $\mathrm{PbI}_{2}$ precursor solution was dissolved in anhydrous DMF:DMSO (9:1=v/v). After $\mathrm{PbI}_{2}$ had cooled down to room temperature, the organic salt solution of FAI:MABr:MACl (60 mg:6 mg:6 mg dissolved in $1 \mathrm{~mL}$ IPA). The hole transporting layer solution was prepared by dissolving Spiro-OMeTAD $(80 \mathrm{mg})$, tBP $(28.5 \mu \mathrm{L})$ and Li-TFSI $(35 \mu \mathrm{L})$ solution (260 mg Li-TFSI in $1 \mathrm{~mL}$ acetonitrile) in $1 \mathrm{~mL}$ chlorobenzene.

Device fabrication: ITO glass was sequentially cleaned in detergent, acetone, isopropanol and deionized water before using, the ITO was cleaned by UVO for $20 \mathrm{~min}$. Then, the $\mathrm{SnO}_{2}$ nanoparticle film $(2.5 \%)$ was spin-coated at $4000 \mathrm{rpm}$ for $30 \mathrm{~s}$, and annealed in ambient air at $150{ }^{\circ} \mathrm{C}$ for $30 \mathrm{~min}$. After that, the1.3M $\mathrm{PbI}_{2}$ precursor solution was spin-coated at $1500 \mathrm{rpm}$ for $30 \mathrm{~s}$ onto $\mathrm{SnO}_{2}$ surface, followed by annealing at $70{ }^{\circ} \mathrm{C}$ for $1 \mathrm{~min}$. Then, the organic salt solution was deposited onto the $\mathrm{PbI}_{2}$ film at $1500 \mathrm{rpm}$ for $30 \mathrm{~s}$, and annealed at $150{ }^{\circ} \mathrm{C}$ for $15 \mathrm{~min}$ in ambient air (50\% humidity). For the FAI healing treatment, different concentration of FAI solution in IPA (from 0 to $5 \mathrm{mg} / \mathrm{mL}$ ) was added on the perovskite film, and instantly spin coated at $1500 \mathrm{rpm}$ for $30 \mathrm{~s}$, and annealed at $150{ }^{\circ} \mathrm{C}$ for 3 min in $\mathrm{N}_{2}$ filled glove box. The Spiro-OMeTAD solution was spin-casted on the perovskite film at $4000 \mathrm{rpm}$ for $30 \mathrm{~s}$. Finally, $80 \mathrm{~nm}$ Au counter electrode was deposited by thermal evaporation using a shadow mask.

Characterizations: The morphology of the perovskite films were characterized by field-emission SEM 
(JEOL JSM-7800F) and AFM (SPA-400). XRD patterns were measured by X-ray diffraction (Rigaku ATX-XRD) with $\mathrm{Cu} \mathrm{K} \alpha$ radiation $(\mathrm{k}=1.5405 \AA)$ at $10^{\circ} \mathrm{min}^{-1}$. The optical characteristics spectra were measured with UV-Vis-NIR spectrophotometer (Cary 5000) in the wavelength from $300 \mathrm{~nm}$ to 900 $\mathrm{nm}$ at room temperature.

Photocurrent density-voltage $(\mathrm{J}-\mathrm{V})$ curves were measured under AM $1.5 \mathrm{G} 1$ sun $\left(100 \mathrm{~mW} / \mathrm{cm}^{2}\right)$ illumination by a solar simulator (HAL-320, ASAHI SPECTRA Co. Ltd., Japan) equipped with a Xenon light. The calibrated light was carried out by a detector (CS-20, ASAHI SPECTRA Co. Ltd., Japan) with silicon reference cell. Photocurrent density-voltage (J-V) curves of solar cells were measured at $25{ }^{\circ} \mathrm{C}$. The scanning step was $40 \mathrm{mV}$ for the $\mathrm{J}-\mathrm{V}$ curve measurement. Unless specified, bias scan from $1.2 \mathrm{~V}$ to $-0.2 \mathrm{~V}$ firstly (reverse scan) and return back (forward scan) with a delay time of $50 \mathrm{~ms}$. The trap density was calculated according to the space-charge limited current (SCLC) method. All devices were measured in the dark from 0 to $5.0 \mathrm{~V}$ with a scanning step of $20 \mathrm{mV}$. The observed response was analyzed according to SCLC theory. A metal mask with a window of $0.1 \mathrm{~cm}^{2}$ was covered on the light illumination side to define the active area of the cell. The spectral response was taken by an external quantum efficiency (EQE) measurement system (QEX10, PV Measurement) with a scanning step of $10 \mathrm{~nm}$. The xenon arc lamp was used as the monochromatic light excitation source and filtered by a double grating. Photoluminescence (PL) and time-resolved photoluminescence (TRPL) measurement were performed by a spectrometer (Edinburgh FS5) at room temperature with laser wavelength and lifetime of $475 \mathrm{~nm}$ and $1000 \mathrm{~ns}$, respectively. The XPS spectra were taken on the Thermo Scientific ESCALAB 250Xi. CLSM images were visualized by using confocal laser scanning microscopy (Leica TCS SP8) with an excitation wavelength at $488 \mathrm{~nm}$. All confocal images were acquired using a $63 \times 1.4$ NA oil-immersion objective lens. 
Transient absorption. $532 \mathrm{~nm}$ light at $1 \mathrm{kHz}$ from Nd:YVO 4 laser (AOT-YVO-25QSPX, Advanced Optical Technologies) was chopped to $500 \mathrm{~Hz}$ (MC2000B, Thorlabs) and acted as the pump light. The probe light initially came from a Ti:sapphire amplifier (Solstice Ace, Spectra Physics) operating at 1 $\mathrm{kHz}$. Nonlinear optical parametric amplifier using a $\beta$-barium borate crystal was adopted to obtain broadband amplification of the seed light from a thin sapphire glass. Part of the probe light was monitored as a reference to account for shot-to-shot variation of laser lights. After the beams were focused into a spectrometer (Shamrock SR 303i, Andor), the signal was detected using a pair of linear image sensors (G11608, Hamamatsu) and read out with a custom-built board (Stresing Entwicklungsburo).

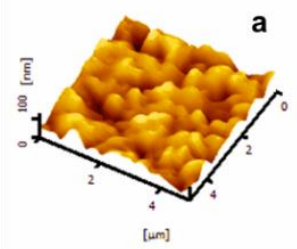

RMS: $21.2 \mathrm{~nm}$

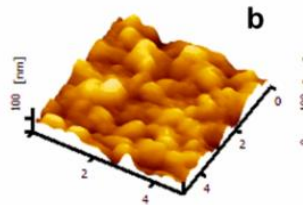

[um]

RMS: $27.0 \mathrm{~nm}$

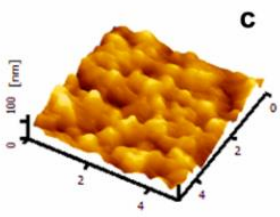

[um]

RMS: 19.6 nm

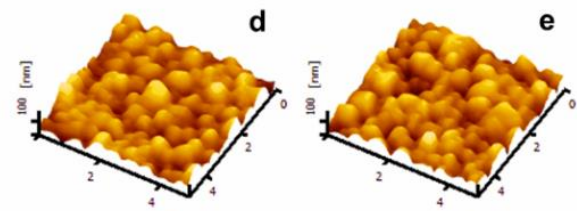

$[\mathrm{mm}]$

RMS: $27.4 \mathrm{~nm}$

RMS: $27.3 \mathrm{~nm}$

Figure S1 Atomic force microscopy images of perovskite films post-treated with different concentration of FAI in IPA: the control sample in (a), pure IPA or $0 \mathrm{mg} / \mathrm{mL}$ in (b), $1 \mathrm{mg} / \mathrm{mL}$ in (c), $3 \mathrm{mg} / \mathrm{mL}$ in (d) and $5 \mathrm{mg} / \mathrm{mL}$ in (e), respectively. "RMS" stands for the root mean squared roughness. 

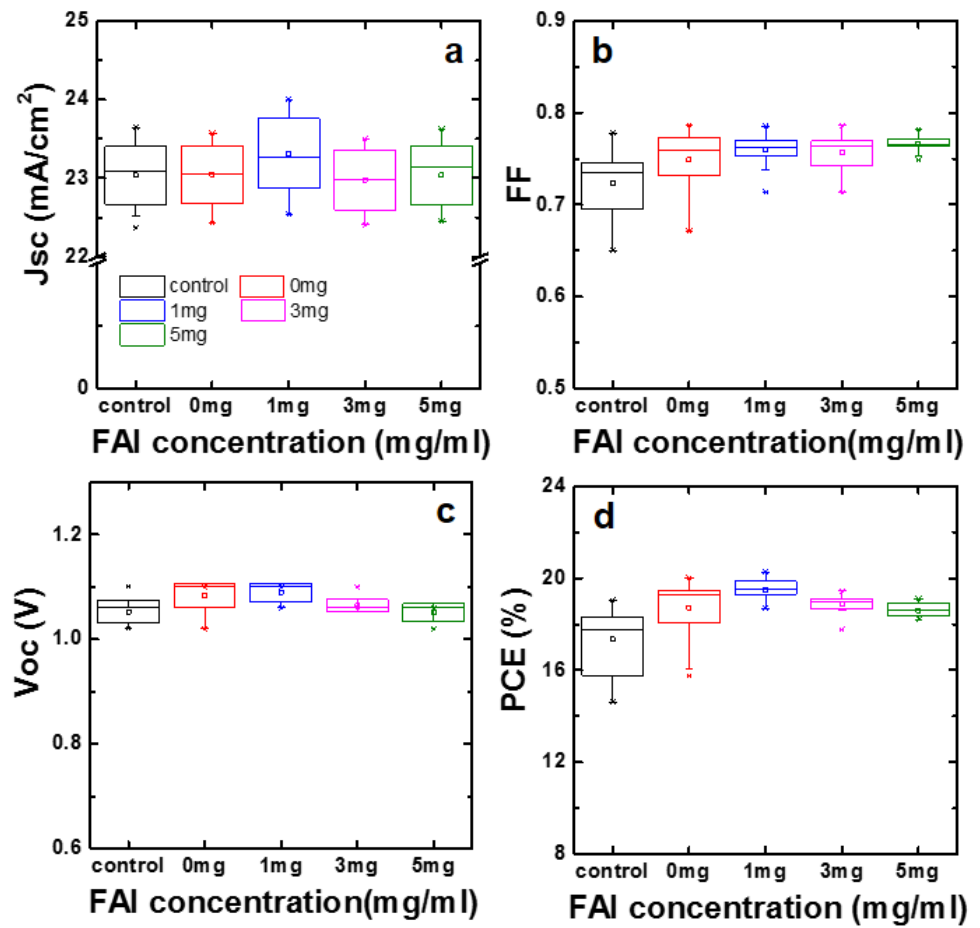

Figure S2 Graphs comparing photovoltaic properties of perovskite solar cells with varied concentration of FAI in IPA: $\mathrm{J}_{\mathrm{SC}}$ in (a), FF in (b), $\mathrm{V}_{\mathrm{OC}}$ in (c) and PCE in (d), respectively. The statistics is based on at least 15 cells from different batches for each conditions.
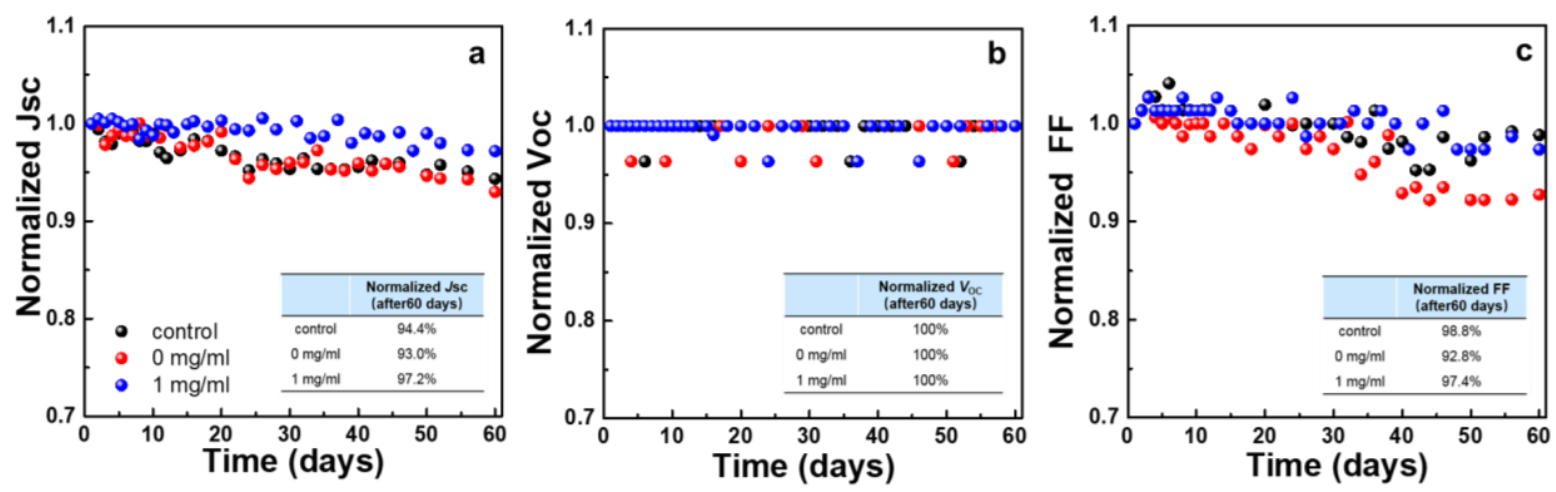

Figure S3. The long-term stability of the control, IPA and FAI healed PSCs with normalized photovoltaic parameters:

$\mathrm{J}_{\mathrm{SC}}$ in (a), $\mathrm{V}_{\mathrm{OC}}$ in (b) and FF in (c). The device performance was continuously measured for 60 days during the storage in a $\mathrm{N}_{2}$ environment. 


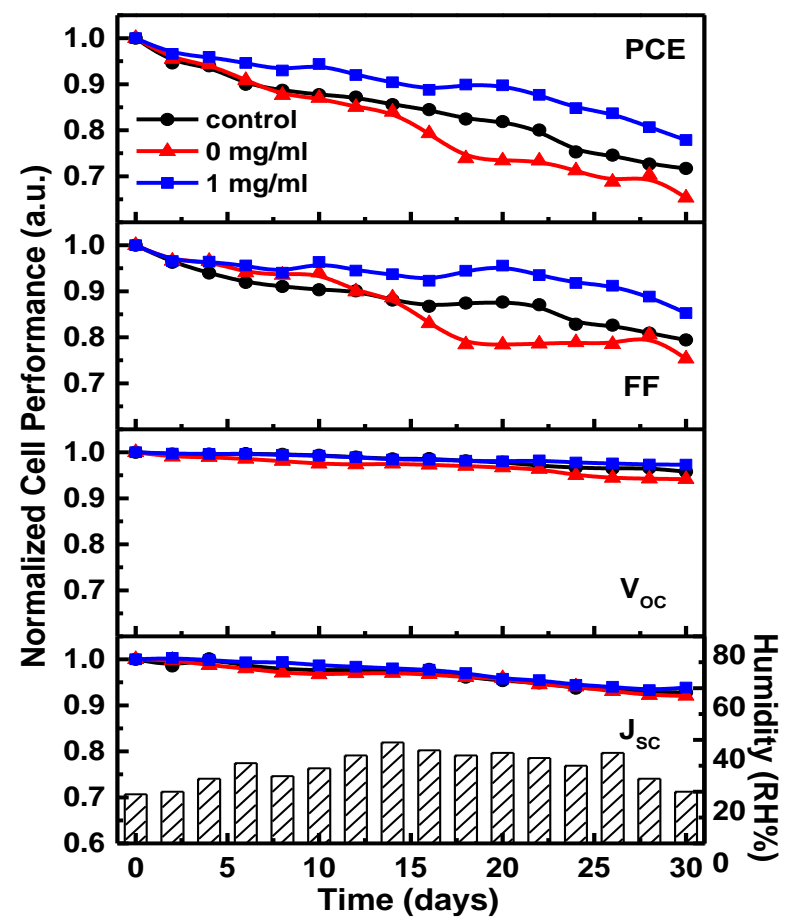

Figure S4 Long-term stability of perovskite solar cells under ambient with varied humidity. All devices are measured without encapsulation but stored in the air for 30 days at room temperature and in the dark. For each condition, at least ten devices were monitored continuously and the results were averaged.
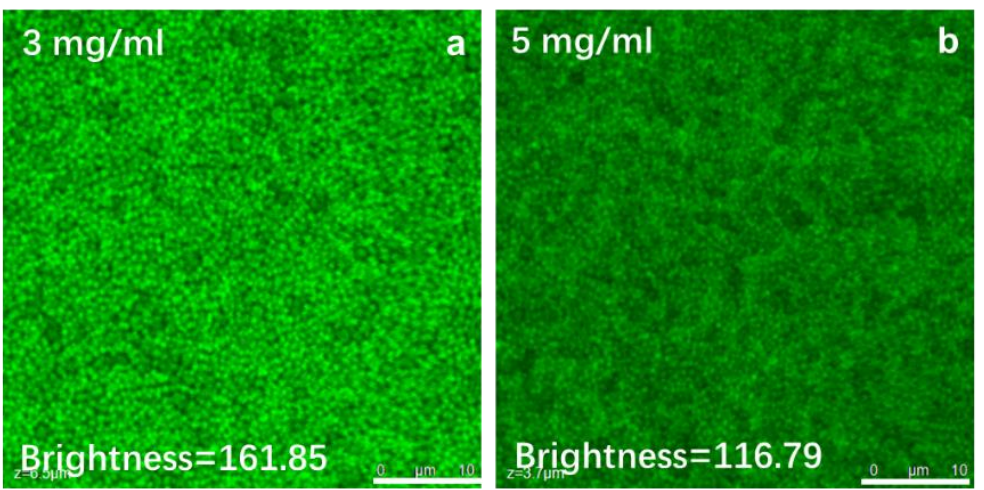

Figure S5 Confocal laser scanning microscopy (CLSM) images of perovskite films treated with $3 \mathrm{mg} / \mathrm{mL}$ and 5 $\mathrm{mg} / \mathrm{mL}$ FAI in IPA. 

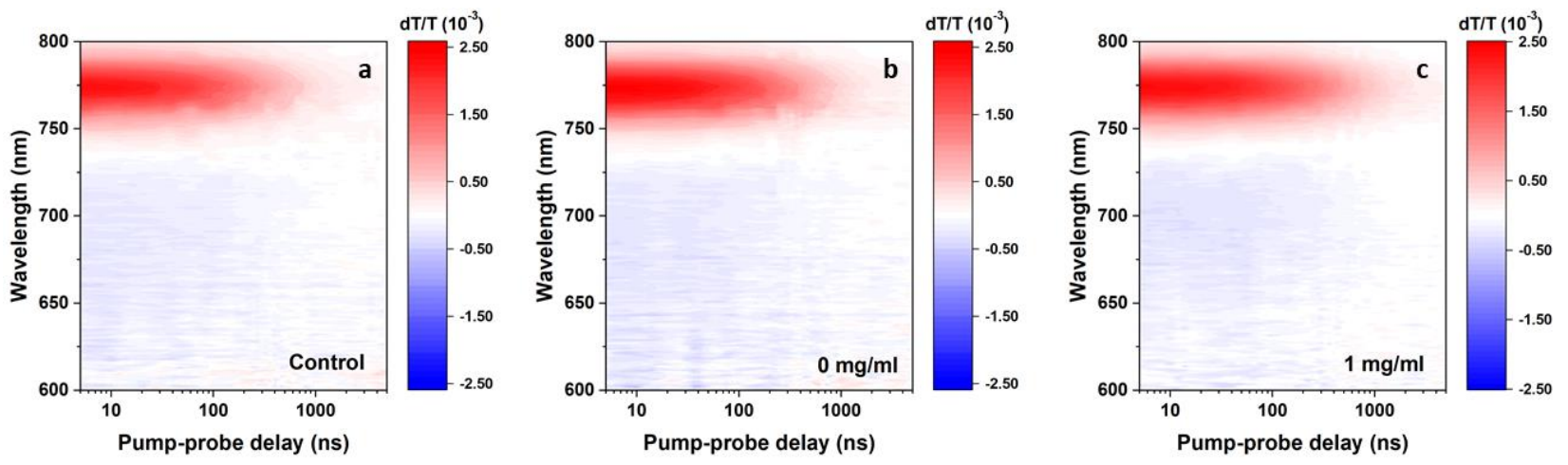

Figure S6 The transient absorption 2D map of the samples of the control, $0 \mathrm{mg} / \mathrm{mL}$ FAI and $1 \mathrm{mg} / \mathrm{mL}$ FAI.
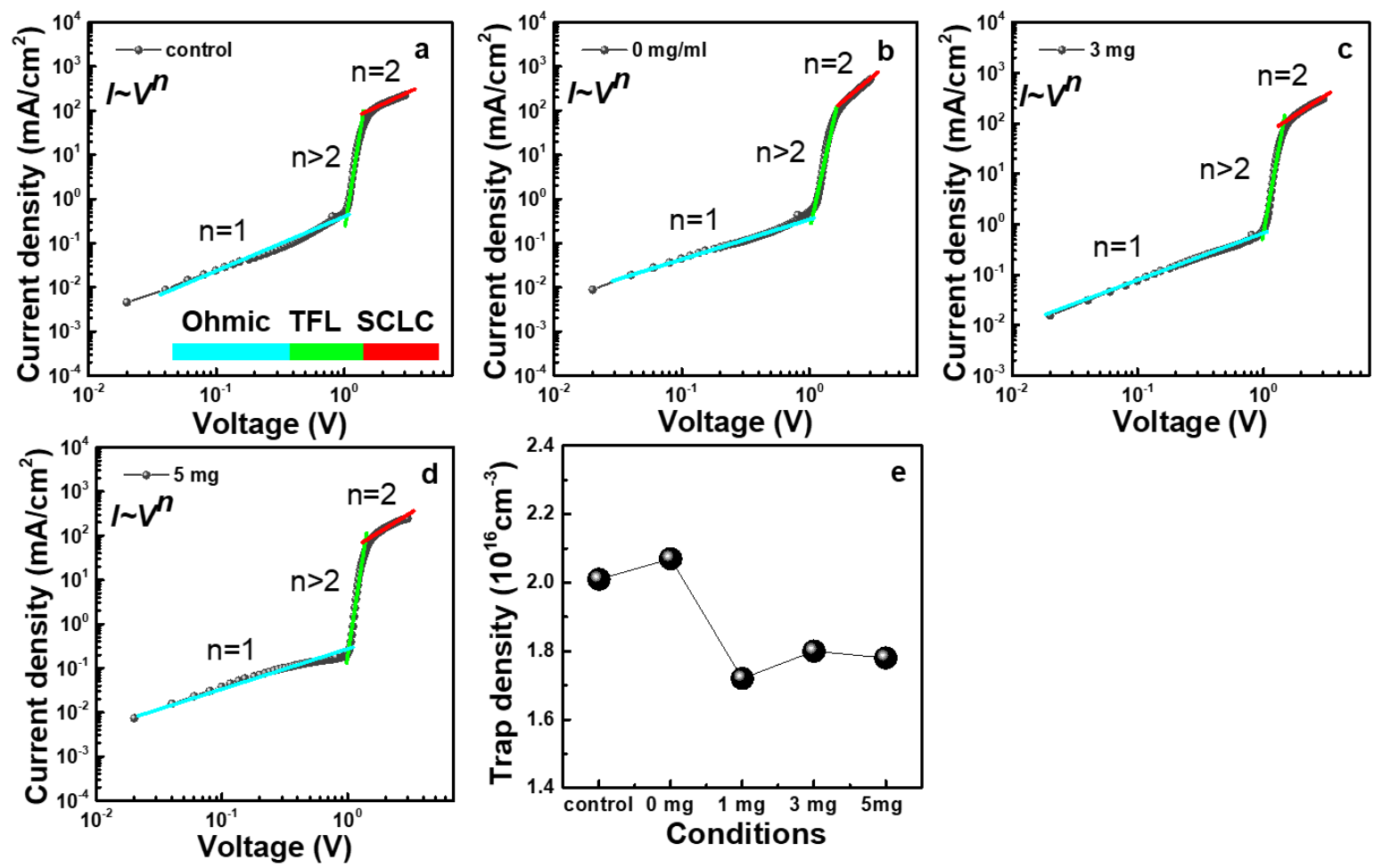

Figure S7 Space charge limited current (SCLC) measurements of perovskite films of the control in (a) or treated by $0 \mathrm{mg} / \mathrm{mL} \mathrm{FAI} / \mathrm{IPA}$ in (b), $3 \mathrm{mg} / \mathrm{mL}$ FAI/IPA in (c), $5 \mathrm{mg} / \mathrm{mL} \mathrm{FAI} / \mathrm{IPA}$ in (d) and the plot of trap density under different healing conditions in (e). 

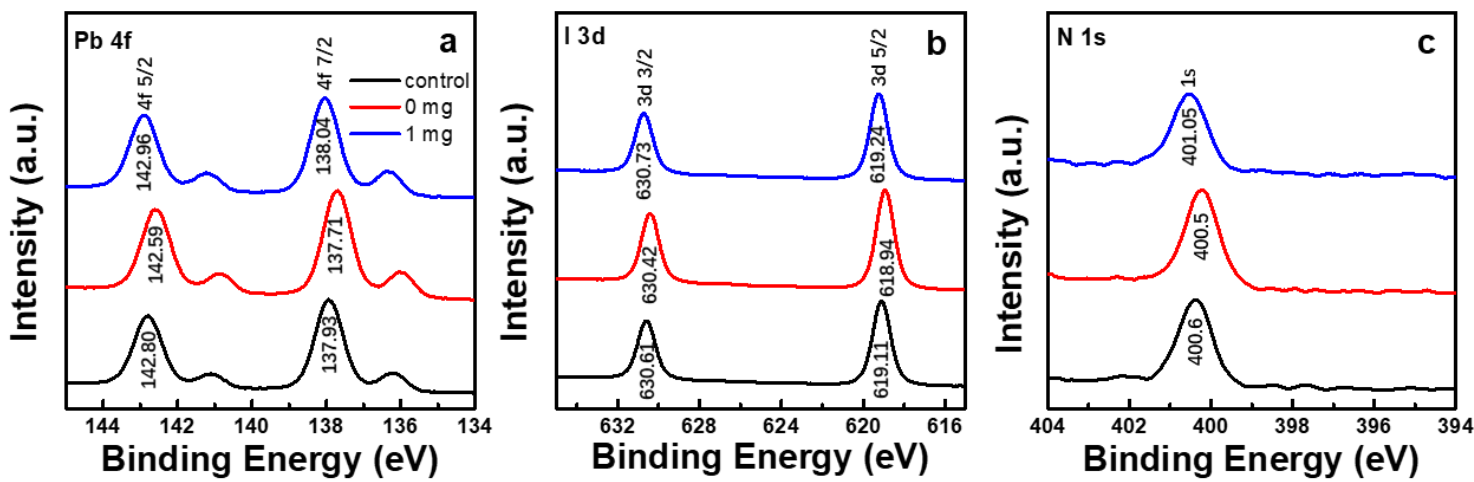

Figure S8. XPS spectra of $\mathrm{Pb} 4 \mathrm{f}$ in (a), I $3 \mathrm{~d}$ in (b) and $\mathrm{N} 1 \mathrm{~s}$ in (c).

A surface-sensitive X-Ray photoelectron spectroscopy (XPS) was used to observe the evolution of chemical states and film composition in Figure S8. The chemical states of $\mathrm{Pb}$, I and $\mathrm{N}$ atoms were detected. Considering that the chemical states of $\mathrm{Pb}$ and $\mathrm{I}$ atoms in $\mathrm{PbI}_{2}$ and perovskite are similar, it is hard to distinguish whether the $\mathrm{Pb}$ and I signals are from either the $\mathrm{PbI}_{2}$ phase or the perovskite phase.

The XPS spectrum of $\mathrm{Pb}(4 \mathrm{f})$ in both of the composition show a doublet due to spin-orbit splitting with the two possible states $\mathrm{Pb}(4 \mathrm{f})_{5 / 2}$ and $\mathrm{Pb}(4 \mathrm{f})_{7 / 2}$ having binding energies $142.80 \mathrm{eV}$ and $137.93 \mathrm{eV}$, respectively for control, $142.59 \mathrm{eV}$ and $137.71 \mathrm{eV}$ for $0 \mathrm{mg}, 142.96 \mathrm{eV}$ and $138.04 \mathrm{eV}$ for $1 \mathrm{mg}$ (Figure 5a). This difference in binding energy for $\mathrm{Pb}(4 \mathrm{f})_{5 / 2}$ and $\mathrm{Pb}(4 \mathrm{f})_{7 / 2}$ peak may be assigned to the residual $\mathrm{PbI}_{2}$ due to IPA treatment in agreement with previous XRD data. Likewise, XPS spectrum of I (3d) in both of the composition show spin-orbit splitting with two possible states I (3d) $)_{3 / 2}$ and $\mathrm{I}(3 \mathrm{~d})_{5 / 2}$ having binding energies $630.61 \mathrm{eV}$ and $619.11 \mathrm{eV}$ for control, $630.42 \mathrm{eV}$ and $618.94 \mathrm{eV}$ for $0 \mathrm{mg}$ and 630.73 $\mathrm{eV}$ and $619.24 \mathrm{eV}$ for $1 \mathrm{mg}$. Again, the difference in binding energy for $\mathrm{I}(3 \mathrm{~d})_{3 / 2}$ and $\mathrm{I}(3 \mathrm{~d})_{5 / 2}$ peak can account for the change in the chemical environment of I due to IPA treatment. 
Table S1 Fitted parameters of decay curves at $780-790 \mathrm{~nm}$ with two exponential components and its average lifetime from transient absorption measurements.

\begin{tabular}{llllll}
\hline Sample & $\mathbf{A}_{\mathbf{1}}$ & $\boldsymbol{\tau}_{\mathbf{1}}(\mathbf{n s})$ & $\mathbf{A}_{\mathbf{2}}$ & $\boldsymbol{\tau}_{\mathbf{2}}(\mathbf{n s})$ & $\boldsymbol{\tau}_{\text {ave }}(\mathbf{n s})$ \\
\hline Control & 0.738 & 278.42 & 0.257 & 2097 & 1595.0 \\
$0 \mathrm{mg} / \mathrm{mL}$ & 0.724 & 218.81 & 0.285 & 2017 & 1628.5 \\
$1 \mathrm{mg} / \mathrm{mL}$ & 0.699 & 304.20 & 0.300 & 2387 & 1910.1 \\
\hline
\end{tabular}

